\title{
Studies on the Influence of Drying Shrinkage Test Procedure, Specimen Geometry, and Boundary Conditions on Free Shrinkage
}

\author{
Bruce Menu, Marc Jolin, and Benoit Bissonnette \\ Department of Civil and Water Engineering, Université Laval, Quebec City, QC, Canada G1V 0A6, \\ Correspondence should be addressed to Bruce Menu; bruce-gandhi.menu.1@ulaval.ca
}

Received 29 August 2017; Accepted 17 October 2017; Published 19 December 2017

Academic Editor: Andrey E. Miroshnichenko

Copyright ( $\odot 2017$ Bruce Menu et al. This is an open access article distributed under the Creative Commons Attribution License, which permits unrestricted use, distribution, and reproduction in any medium, provided the original work is properly cited.

\begin{abstract}
Although considerable progress has been made in enhancing the use and interpretation of free ring shrinkage test, little is known about the impact of the test procedure, the specimen geometry, the surface area-to-volume (S/V) ratio exposed to drying, and the boundary conditions (sealing configuration) on the measured shrinkage. This paper highlights recent findings illustrating the influence of the test procedure, the S/V ratio exposed to drying, the geometry of specimen, and the boundary conditions. A series of experimental results are presented from free shrinkage on ring test specimens to illustrate that the test procedure can significantly influence the measured free shrinkage. A second series of experimental results are presented from specimens with different geometries and S/V ratio exposed to drying to illustrate that drying shrinkage is dependent on both the specimen geometry and the surface exposed to drying. Test results further show that, even for the same S/V ratio exposed to drying, shrinkage is strongly dependent on the specimen's geometry and boundary conditions.
\end{abstract}

\section{Introduction}

Concrete undergoes significant volume changes due to the evolution of the moisture or water content within its porosity. Concrete swells when exposed to moisture, while it shrinks when exposed to relatively lower relative humidity. The net relative humidity reduction inside the pores changes the local thermodynamic equilibrium, which in turn affects the mechanical equilibrium, translating into a macroscopical contraction of the cement paste referred to as shrinkage. Concrete is very sensitive to shrinkage cracking at the early ages [1] particularly due to the rapid development of drying shrinkage. Early-age cracking can occur in concrete if the free shrinkage is prevented by the surrounding structure [2]. This is because concrete has low tensile strain capacity and is most sensitive to internal stresses during early ages immediately after casting [3]. Degradation of concrete structural elements due to shrinkage of concrete, during its drying stage, usually leads to significant costs of repairing [4]. The magnitude of shrinkage is dependent on many factors, particularly the water content of the fresh concrete.

Free or unrestrained shrinkage test methods are used to evaluate the shrinkage potential of concrete. In these methods, concrete specimens are unrestrained and hence allowed to change volume and shrink freely in an environmentally controlled chamber with a constant temperature and relative humidity (RH). The change in length is measured at regular intervals for a specified period. Free shrinkage is typically measured uniaxially on prismatic test specimens (ASTM C157 [5]) due to the simplicity of data interpretation. However, it may also be measured on test specimens with different geometries such as the free ring test developed as a complementary test procedure for the restrained ring test. Regardless, to directly use prismatic shrinkage results in ring test analysis, a generally accepted idea is to prepare prismatic specimen with the same $\mathrm{S} / \mathrm{V}$ ratio as the restrained ring specimen. However, in reality, ring shrinkage may not always correspond to prismatic shrinkage with the equal S/V ratio. Researchers have published a great quantity of scientific literature and technical reports on the ring test in the past few decades [6-9]. However, little work is focused on the impact of the free ring test procedure, $\mathrm{S} / \mathrm{V}$ exposed to drying, and boundary conditions (i.e., drying direction) on the measured shrinkage.

The present study is part of ongoing research on the durability of concrete and shotcrete mixtures. In this paper, 


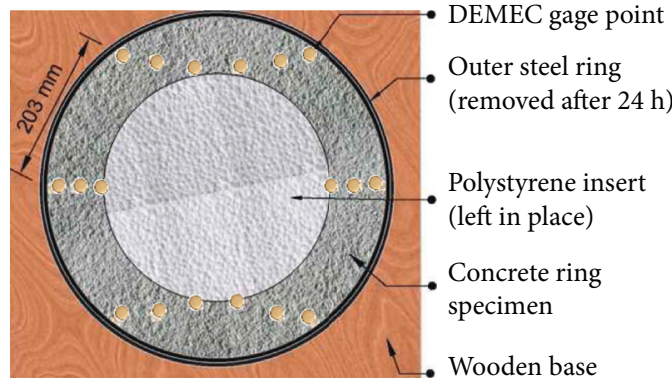

(a)

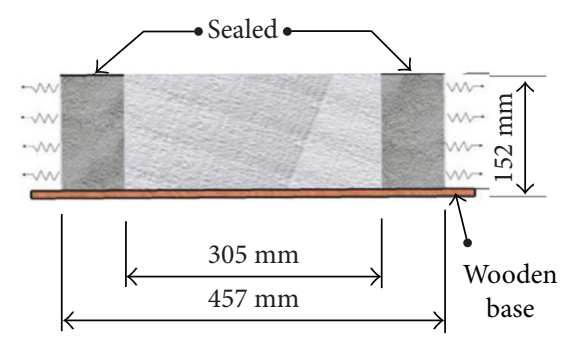

(b)

Figure 1: Dimensions of free ring setup (radial drying condition illustrated). (a) Top view. (b) Front view.

the free ring test is used to extend the interpretation of the restrained shrinkage ring test experiment. The free ring specimen used in this studies is based on the AASHTO [10] restrained ring test specimen configuration shown in Figure 1. This paper highlights the influence of the free ring test procedure on the measured drying shrinkage which is important because free shrinkage is mostly used to estimate creep and stress relaxation [11-13] of concrete. The influence of geometry, surface area-to-volume (S/V) ratio exposed to drying, and drying direction on the measured drying shrinkage is discussed.

\section{Research Significance}

The research was undertaken to investigate the influence of the ring test procedure on the measured shrinkage. In addition to the need for evaluating the shrinkage versus time curve in the most consistent fashion for analytical calculations, such validation is made necessary for practical purposes, as the ASTM C157 procedure is ill-suited for unconventional placement methods such as shotcrete. More importantly, improving the free ring test method is necessary as recent studies have demonstrated the increasing use of free drying shrinkage in combination with restrained shrinkage to evaluate creep and stress relaxation of concrete.

\section{Experimental Program}

To investigate the influence of specimen geometry, surfaceto-volume $(\mathrm{S} / \mathrm{V})$ ratio exposed to drying, the ring test procedure (i.e., DEMEC (DEmountable MEChanical) gage point locations), and surface sealing (axial versus radial drying) on free shrinkage, both prismatic (linear) and ring specimens were prepared. The overall project evolves around shotcrete durability and performance; a shotcrete mixture (maximum coarse aggregate size of $10 \mathrm{~mm}$ ) was used for producing concrete mixtures. The concrete mixture used was selected to resemble that of dry-mix shotcrete design (ACI 506 Guide to Shotcrete [14]). The research was aimed at optimising the free ring shrinkage test procedure and correlating the results with the restrained ring test results. Hence, the method of placement (cast or sprayed) did not really matter, and gravitational casting was selected for simplicity (the reader can refer to [15] for a procedure developed to evaluate restrained and free shrinkage of sprayed ring test specimens). No admixture was added to the $\mathrm{w} / \mathrm{cm}=0.60$ mixture, but a naphthalene-based superplasticizer and air-entraining agent were added to $\mathrm{w} / \mathrm{cm}=$ 0.45 mixture to obtain the desired workability due to the low water-to-cement $(\mathrm{w} / \mathrm{cm})$ ratio. The concrete mixture proportions used in the study are provided in Table 1. The compressive strength, splitting tensile strength, and modulus of elasticity were also determined in accordance with ASTM C39, C496, and C469 test methods. Contrary to restrained ring test where shrinkage of concrete is not permitted, in the free ring test, however, the concrete specimen is not internally restrained and hence can shrink "freely." DEMEC gages are installed on top of the ring specimens for length change measurements. The following sections briefly describe the implemented free shrinkage test methods in this study.

3.1. Free Uniaxial Test Specimens. Acknowledging that drying shrinkage is dependent on the S/V ratio exposed to drying $[16,17]$, the first step was basically to measure free shrinkage using prismatic specimens with different $\mathrm{S} / \mathrm{V}$ ratios. The $\mathrm{S} / \mathrm{V}$ ratios are summarised in Table 2 . The aim was to investigate the influence of different exposure conditions on drying shrinkage and to simulate the same exposed $\mathrm{S} / \mathrm{V}$ ratios as for the ring specimens. Free uniaxial shrinkage was evaluated using a modified version of the ASTM C157 test method. Nine prismatic $75 \times 75 \times 285 \mathrm{~mm}$ prismatic concrete specimens were cast for each mixture. The specimens were moist cured for $231 / 2 \pm 1 / 2 h$ and then demolded. The test procedure was modified such that, after demolding, the specimens were moist cured for 2 more days (i.e., age 3-days). The specimens were placed in an environmental chamber with a constant $\mathrm{RH}(50 \%)$ and temperature $\left(21 \pm 1.7^{\circ} \mathrm{C}\right)$.

The length change was monitored with the aid of a comparator upon exposure to drying to imitate the free ring specimen procedure. Three specimens were unsealed while six specimens were sealed such that, in each case, three specimens have equal S/V ratio as the ring specimens drying from the radial direction and axial direction as shown in Figure 2. Drying is thus permitted only from the exposed sides of the concrete specimens. It should be mentioned that 
TABLE 1: Composition of the investigated concrete mixtures.

\begin{tabular}{lcccccc}
\hline $\mathrm{w} / \mathrm{cm}$ & $\begin{array}{c}\text { OPC cement } \\
\left(\mathrm{kg} / \mathrm{m}^{3}\right)\end{array}$ & $\begin{array}{c}2.5-10 \mathrm{~mm} \text { crushed } \\
\text { limestone }\left(\mathrm{kg} / \mathrm{m}^{3}\right)\end{array}$ & $\begin{array}{c}0.08-5 \mathrm{~mm} \text { natural } \\
\text { sand }\left(\mathrm{kg} / \mathrm{m}^{3}\right)\end{array}$ & $\begin{array}{c}\text { Water } \\
\left(\mathrm{kg} / \mathrm{m}^{3}\right)\end{array}$ & $\begin{array}{c}\text { Superplasticizer } \\
\left(\mathrm{kg} / \mathrm{m}^{3}\right)\end{array}$ & $\begin{array}{c}\text { Air-entraining } \\
\mathrm{agent}\left(\mathrm{kg} / \mathrm{m}^{3}\right)\end{array}$ \\
\hline 0.45 & 445 & 736 & 1054 & 197 & 5 & 0.16 \\
0.60 & 417 & 689 & 988 & 247 & - \\
\hline
\end{tabular}

TABle 2: Dimensions and S/V ratios of specimens.

\begin{tabular}{lccc}
\hline Specimen & Dimensions $(\mathrm{mm})$ & Drying condition & $\mathrm{S} / \mathrm{V}\left(\mathrm{m}^{-1}\right)$ \\
\hline Prismatic & $75 \times 75 \times 285$ & All surfaces & 60.4 \\
& & No surface & 0 \\
\multirow{2}{*}{ Ring } & $H=152.0$ & Radial & 15.8 \\
& $R_{\mathrm{ic}}=152.5$ & Axial & 13.2 \\
& $R_{\mathrm{oc}}=228.5$ & & \\
\hline
\end{tabular}

$H=$ height; $R_{\mathrm{ic}}=$ inner radius; $R_{\mathrm{oc}}=$ outer radius
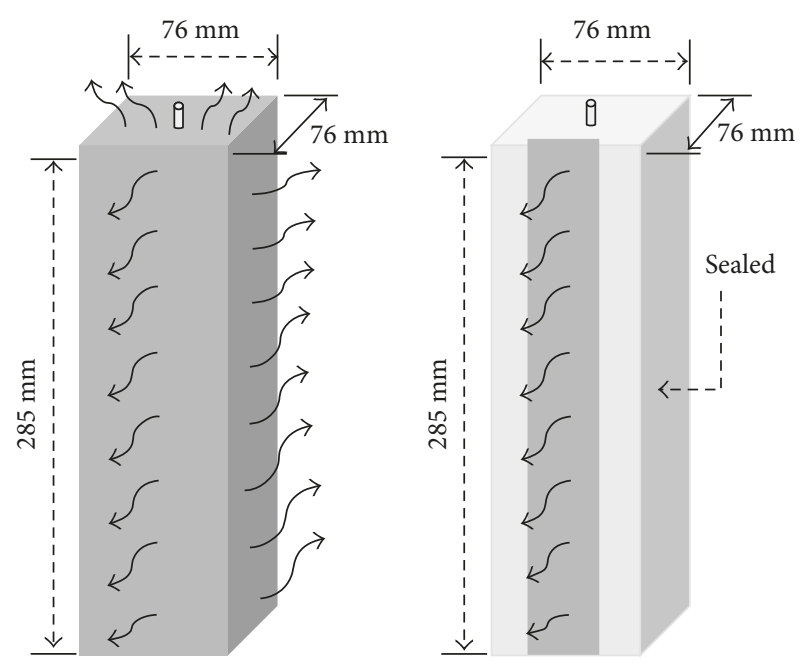

FIgURE 2: ASTM C157 specimens.

although the linear specimens were sealed to have the same $\mathrm{S} / \mathrm{V}$ exposed as the radial and axial drying in the ring specimens, they can in fact only mimic the axial drying direction conditions. Three supplemental specimens were cast and completely sealed on all surfaces $(\mathrm{S} / \mathrm{V}=0)$ after $24 \mathrm{~h}$ of moist curing.

3.2. Free Ring Test Specimens. The goal of the free ring test was to investigate the influence of the DEMEC gage point location and the sealing configuration (radial versus axial drying) on the measured shrinkage. It should be mentioned that the dependence of drying conditions on shrinkage of concrete has been previously shown by Moon et al. [7, 18]. These papers however point toward the importance of drying conditions in restrained shrinkage (cracking studies), while the present paper focuses on the influence of drying conditions on free shrinkage. Three different DEMEC gage point locations were investigated. The locations were chosen such that it would cover the range of possibilities, with measurements near the inner radius, at mid-width of the concrete ring specimen, and at the outer edge of the

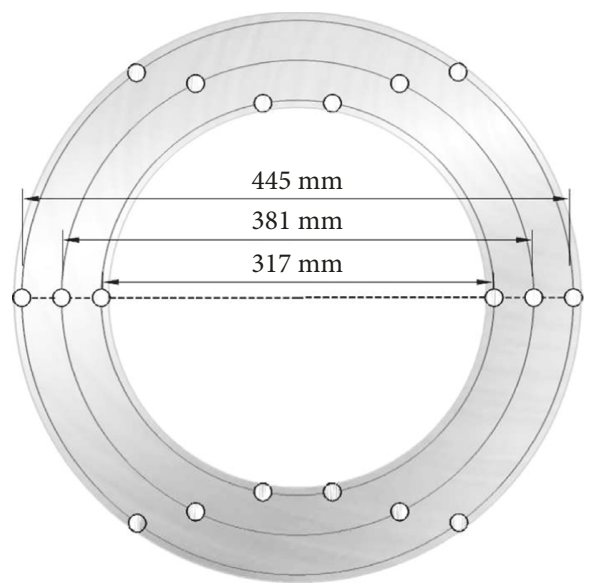

Figure 3: Template for positioning of the DEMEC point discs on the free ring-shape specimens.

concrete ring. A template was designed for ensuring accurate positioning of the gages (as illustrated in Figure 3). The free ring test procedure consists of replacing the steel ring in the restrained shrinkage test (AASHTO T334-08, formerly AASHTO PP 34-99) with a material having a very low stiffness with respect to the concrete ring (such as white polystyrene). The choice of a polystyrene ring was basically to facilitate the test procedure and to mimic the companion restrained test specimen as closely as possible. The aim was also to reduce the time necessary for testing (casting, demolding, placing DEMECs, etc.) and to also limit manipulation of the rings at early age. Moreover, the restraint due to the polystyrene ring is negligible as it has an elastic modulus of about 2.2 MPa compared with steel ring used in the restrained shrinkage which is about $200 \mathrm{MPa}$. Needless to say, the choice of a removable center ring was also considered at the initial stages. In this test, a $152 \mathrm{~mm}$ high and $76 \mathrm{~mm}$ thick ring of concrete is then cast around the polystyrene ring having a diameter of $305 \mathrm{~mm}$. Details of the specimen configuration are shown in Figure 1. At least four concrete ring specimens were cast for each concrete mixture to measure the free drying shrinkage. Upon casting, the freshly placed concrete was consolidated in the mold. All specimens were left in their mold for the first 24 hours after casting and covered with wet burlap and plastic sheets. After 24 hours of curing, the exterior wall of the mold is removed, and the specimens are cured for 2 more days (age 3-days). After curing, DEMEC gages are installed on top of the specimens for length change measurements. The ring specimens are sealed with an adhesive aluminium tape to restrict drying to only the unsealed surfaces. At least two specimens each were sealed on the top (and bottom) and the outer circumference. The test specimens drying 


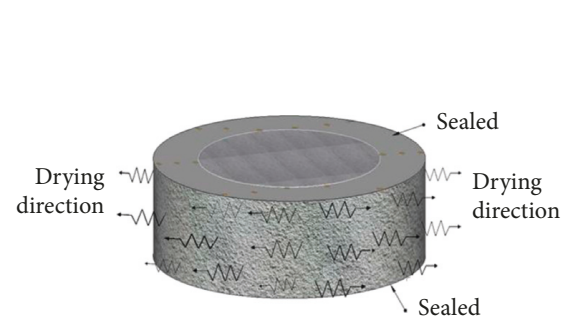

(a)

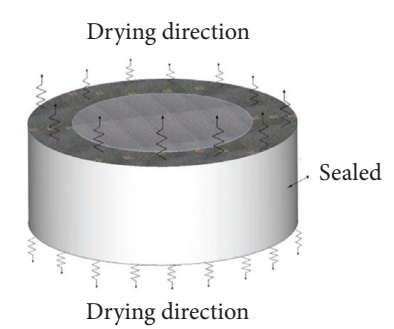

(b)

Figure 4: Free ring specimen with DEMEC. (a) Sealed on top (and bottom) and (b) sealed on the outer circumferential surface.

from the outer radial surface or so-called "circumferential drying" (a) and the axial sides or so-called "top and bottom drying" (b) are shown in Figure 4. The specimens were exposed to drying under standard conditions $\left(21 \pm 1.7^{\circ} \mathrm{C}\right.$ and $50 \pm 4 \% \mathrm{RH})$.

The initial zero measurement was taken immediately after curing and sealing (age 3 days), and the length change was monitored during the entire drying period. A digital DEMEC (DEmountable MEChanical digital strain gage secured on a reference Invar bar) was used for measuring the length change between the DEMEC points. In general, the shrinkage recorded on each ring specimen is the average recorded on the three DEMEC gage point locations (inner, mid-width, and outer). The free drying shrinkage strain was calculated using the following expression:

$$
\varepsilon_{\mathrm{sh}}=\frac{\Delta L}{G}
$$

where $\varepsilon_{\text {sh }}$ is the free shrinkage, $\Delta L$ is the change in length, and $G$ is the gage length.

3.3. Characterization of Test Specimens. Twenty-one $100 \times 200 \mathrm{~mm}(4 \times 8$ in.) cylinders were also prepared for each tested concrete mixture. Four cylinders per mixtures were tested in compression at 3, 7, and 28 days after casting to determine compressive strength following ASTM C39, two of which were also used to determine the modulus of elasticity and Poisson's ratio in accordance with ASTM C469. Three supplemental cylinders were used to determine the splitting tensile strength at 3, 7, and 28 days after casting in accordance with ASTM C496. After casting of specimens, they were kept in the mold and covered with wet burlaps and a $0.15 \mathrm{~mm}$ polyethylene sheet for $231 / 2 \pm 1 / 2$ hours and subsequently stored under standard conditions $\left(23 \pm 1.7^{\circ} \mathrm{C}\right.$ and $100 \% \mathrm{RH}$ ) until testing age.

\section{Test Results and Discussion}

4.1. Mechanical Properties of Concrete. The mechanical properties were measured at ages of 3,7 , and 28 days using the cylindrical specimens with the same w/cm of 0.45 and 0.60 mixtures. The compressive strength result is shown in Figure 5 while the splitting tensile strength elastic modulus and Poisson's ratio are summarized in Table 3. In general, the compressive strength, elastic modulus, and tensile strength show an overall steady increase with increase in

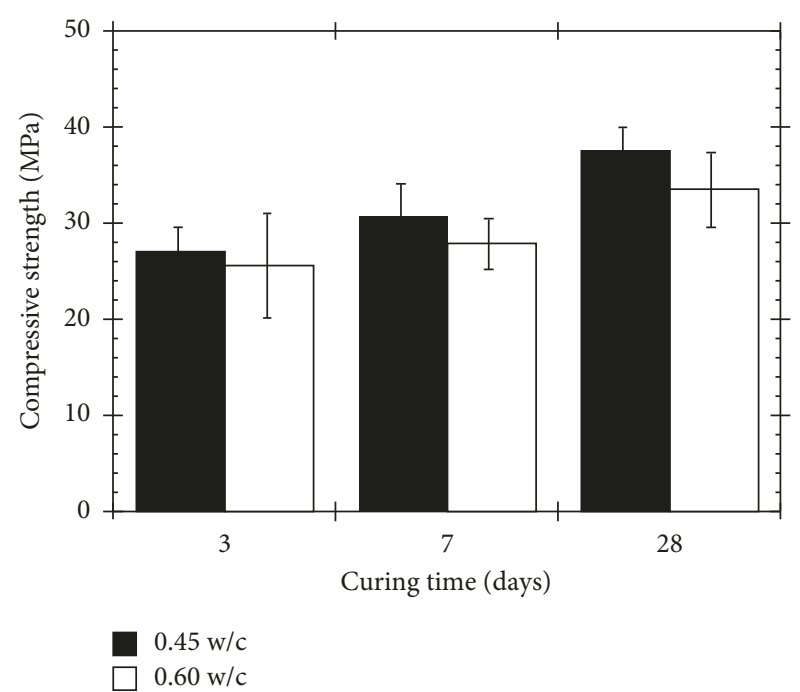

FIGURE 5: Compressive strength of concrete (error bars represent the coefficient of variation).

curing age but a decrease with increase in $\mathrm{w} / \mathrm{cm}$ ratio. The determined Poisson's ratio values in this study, however, appear to decrease with increase in strength and maturity of concrete but a slight increase with increase in $\mathrm{w} / \mathrm{cm}$ ratio. Interestingly, similar results were reported in other studies [19]. Poisson's ratio of concrete must therefore not be a constant value as commonly used. Admittedly, Poisson's ratio is little difficult to quantify and even more so to interpret. However, it is needed for the evaluation of elastic stress and stress relaxation properties of concrete.

4.2. Free Linear Shrinkage of Concrete. The average free shrinkage recorded on prismatic specimens with different $S / \mathrm{V}$ ratios is presented in the two graphs of Figure 6, corresponding, respectively, to the $0.45 \mathrm{w} / \mathrm{cm}$ and $0.60 \mathrm{w} / \mathrm{cm} \mathrm{mix-}$ tures. On each graph, the $x$-axis is the time elapsed since drying initiation, which started in all cases at the age of 3 days. In the case of the sealed specimens, they were covered and monitored for length change starting at the age of one day. Hence, the curves plotted for these specimens in Figure 6 omit the strains recorded between one and three days. It should be noted that the length change curves of the sealed specimens correspond to self-desiccation shrinkage, while the test results of the drying specimens (nonsealed and 
TABLE 3: Mechanical properties.

\begin{tabular}{|c|c|c|c|c|c|c|}
\hline \multirow{2}{*}{ Age (days) } & \multicolumn{3}{|c|}{$\mathrm{w} / \mathrm{cm} 0.45$} & \multicolumn{3}{|c|}{$\mathrm{w} / \mathrm{cm} 0.60$} \\
\hline & $f_{t}(\mathrm{MPa})$ & $E_{c}(\mathrm{GPa})$ & $\mu$ & $f_{t}(\mathrm{MPa})$ & $E_{c}(\mathrm{GPa})$ & $\mu$ \\
\hline 3 & 2.4 & 25.8 & $0.18 \pm 0.012$ & 2.4 & 25.4 & $0.19 \pm 0.014$ \\
\hline 7 & 2.6 & 26.8 & $0.17 \pm 0.009$ & 2.5 & 26.3 & $0.18 \pm 0.009$ \\
\hline 28 & 3.2 & 30.0 & $0.16 \pm 0.007$ & 2.7 & 28.8 & $0.17 \pm 0.011$ \\
\hline
\end{tabular}

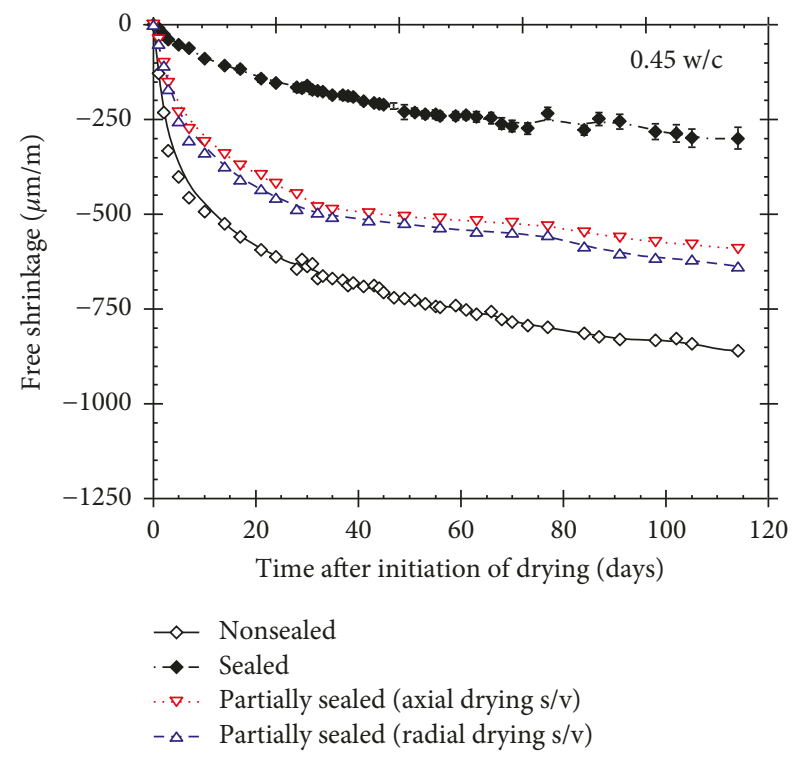

(a)

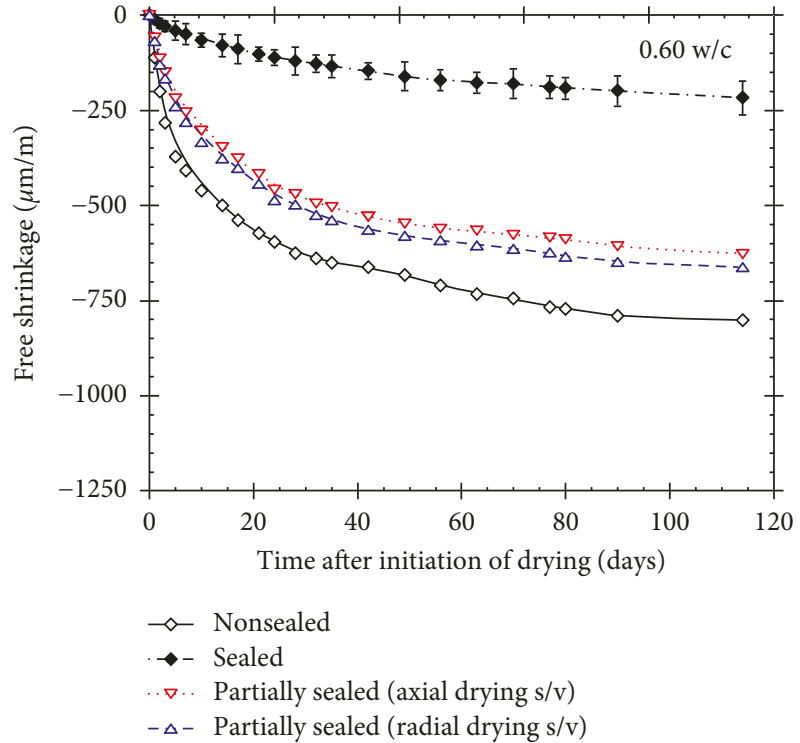

(b)

FIGURE 6: ASTM C157 modified shrinkage strain results obtained under various drying exposure conditions. (a) w/cm 0.45 mixture, (b) $\mathrm{w} / \mathrm{cm} 0.60$ mixture.

partially sealed) include the effect of both autogenous shrinkage and drying shrinkage, referred to hereafter as the total free shrinkage. The results obtained in drying conditions are quite similar for both concretes (very little differences actually observed within experimental variations). We would actually have expected the $0.60 \mathrm{w} / \mathrm{cm}$ mixture to exhibit more total shrinkage, especially considering its larger paste content.

It was also observed that, for both $\mathrm{w} / \mathrm{cm}=0.45$ and 0.60 mixtures, the amount of total free shrinkage appears to be dependent on the surface area exposed to drying. In general, the higher surface-to-volume ratio resulted in the highest magnitude of shrinkage recorded due to faster drying in higher $\mathrm{S} / \mathrm{V}$ ratio specimens. These observations are consistent with those of some previous studies [17] although the specimens in the latter were moist cured for one day, and the shrinkage was monitored up to only 28 days. In fact, this was to be expected since drying is a diffusion-based process and drying shrinkage depends on the internal relative humidity change and hence on the $\mathrm{S} / \mathrm{V}$ ratio exposed to drying. As expected, Figure 6 shows that sealed shrinkage is higher in mixtures with $\mathrm{w} / \mathrm{cm}=0.45$ than $\mathrm{w} / \mathrm{cm}=0.60$. The sealed strain values for the $\mathrm{w} / \mathrm{cm}=0.45$ were similar to those reported by Mors [20] for mixtures with $\mathrm{w} / \mathrm{cm}=0.45$.
4.3. Free Ring Shrinkage of Concrete. The first objective of this work is to investigate the influence of the free ring test procedure on the shrinkage measured on the specimen. Three different DEMEC gage point locations were investigated. The locations were chosen such that it would cover the range of possibilities, with measurements near the inner radius, at mid-width of the concrete ring specimen and at the outer edge of the concrete ring. A template was designed for ensuring accurate positioning of the gages (as illustrated in Figure 3). The shrinkage recorded for each ring is an average of measurements performed for four sets of DEMEC points around the circumference. At least two sets of ring specimens are cast for each mixture. The ring specimens could dry from either the radial or the axial direction. A comparison of the free ring shrinkage strain measurements at the different locations is presented in Figure 7. Overall, the results indicate that moisture gradient within the concrete ring thickness affects the recorded shrinkage strains. Implying that the location at which the shrinkage is measured on the ring specimen will influence the magnitude of free shrinkage measured. Indeed, it was observed that, for both $\mathrm{w} / \mathrm{cm}=0.45$ and $\mathrm{w} / \mathrm{cm}=0.60 \mathrm{mix}-$ tures, the total free shrinkage differs to a certain degree depending on the DEMEC point location (inner, mid-width, and outer). In general, higher shrinkage rates were recorded 


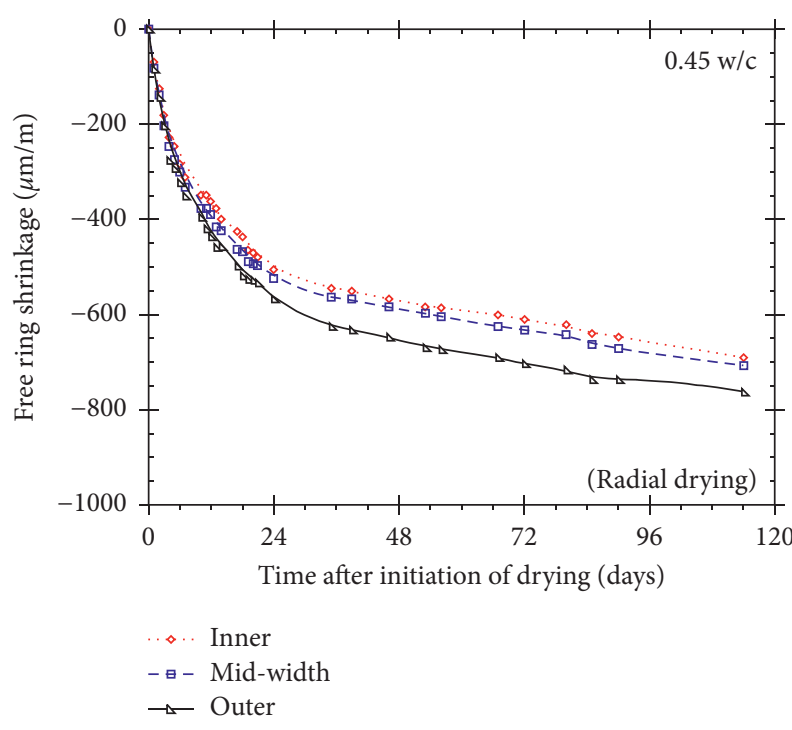

(a)

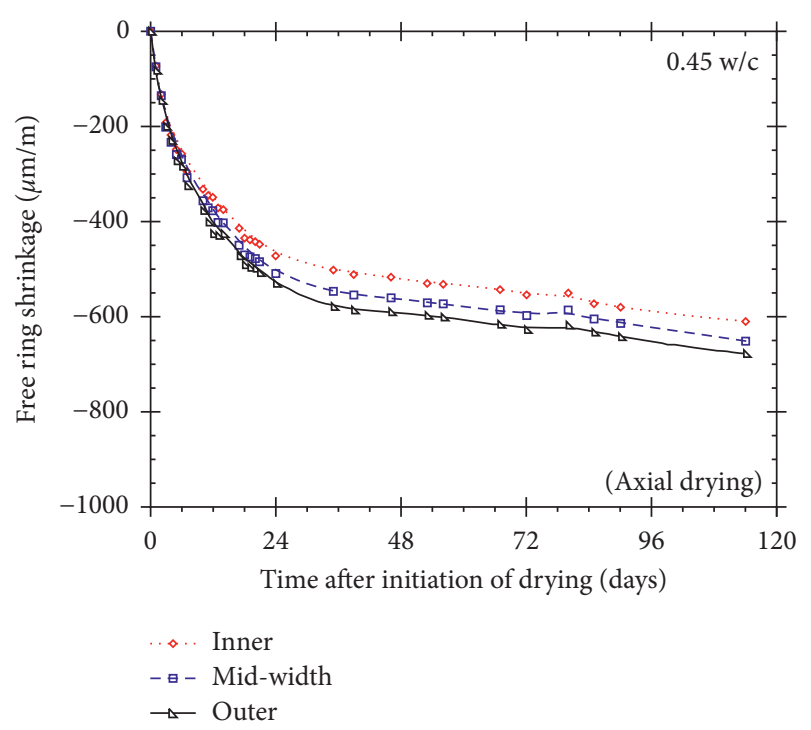

(c)

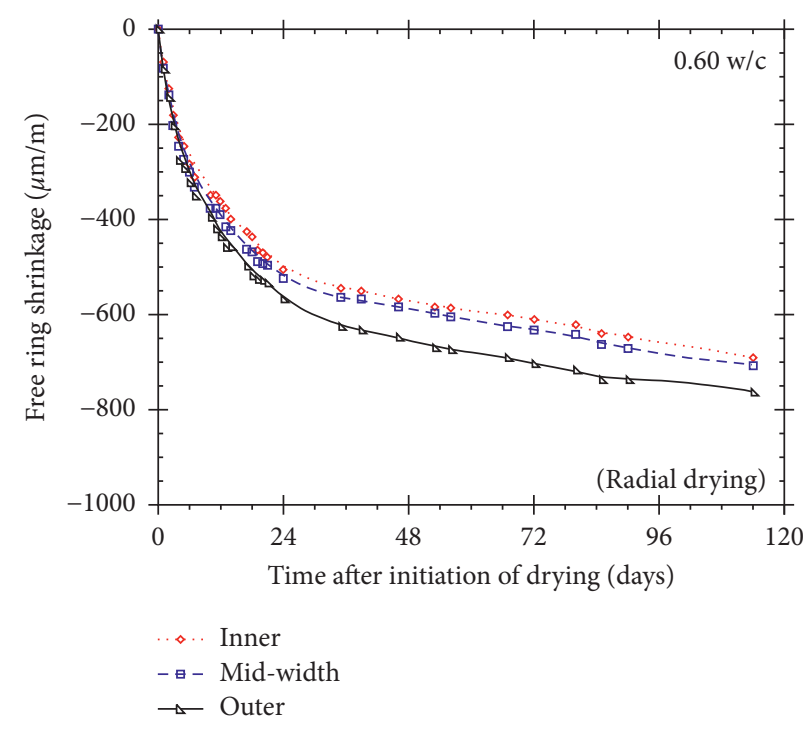

(b)

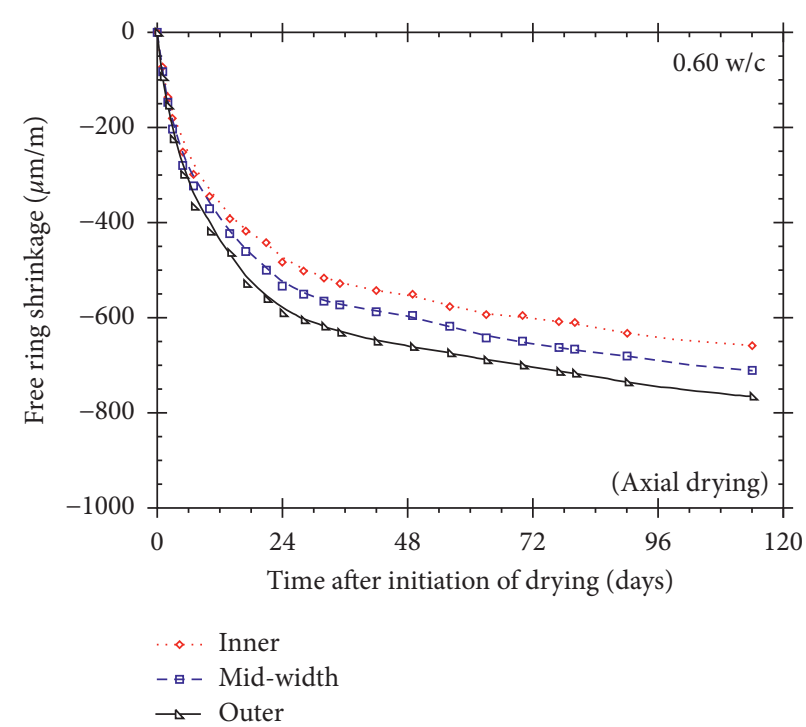

(d)

FiguRE 7: The influence of DEMEC gage positioning on the measured free ring shrinkage strain. (a) w/cm 0.45 radial drying specimen, (b) $\mathrm{w} / \mathrm{cm} 0.60$ radial drying specimen, (c) w/cm 0.45 axial drying specimen, (d) w/cm 0.60 axial drying specimen.

at the outer location on the concrete ring specimen for both drying directions. This is attributed to the fact that the ring specimens do not shrink at the same rate at all three locations in the ring since moisture varies across the thick concrete ring wall.

The results further indicate that the drying direction (i.e., boundary condition) in the ring specimen significantly influenced the free shrinkage recorded at the different locations on the ring specimens (inner, mid-width, and outer). Fundamentally, this is to be expected since the boundary conditions imposed on the ring specimen will affect the nature of moisture loss (uniform or nonuniform) along the radius of the ring. Naturally, drying shrinkage is related to moisture loss from the concrete specimen; hence, the rate of shrinkage strain will consequently be dictated by the nature of moisture loss. It can be observed that for specimens drying from axial direction, shrinkage strain increases linearly from the inner to the outer radius. This is likely because, in specimen drying from the axial direction, moisture loss is uniform along the radial direction but not along the height direction [7]. As such, due to the geometry of the ring specimen, the three DEMEC point locations on top of the specimen will not have equal drying rate. Hence, they naturally will shrink at different rates, linearly from the inner to the outer radius. However, in specimens drying from the radial direction, there was no significant difference 


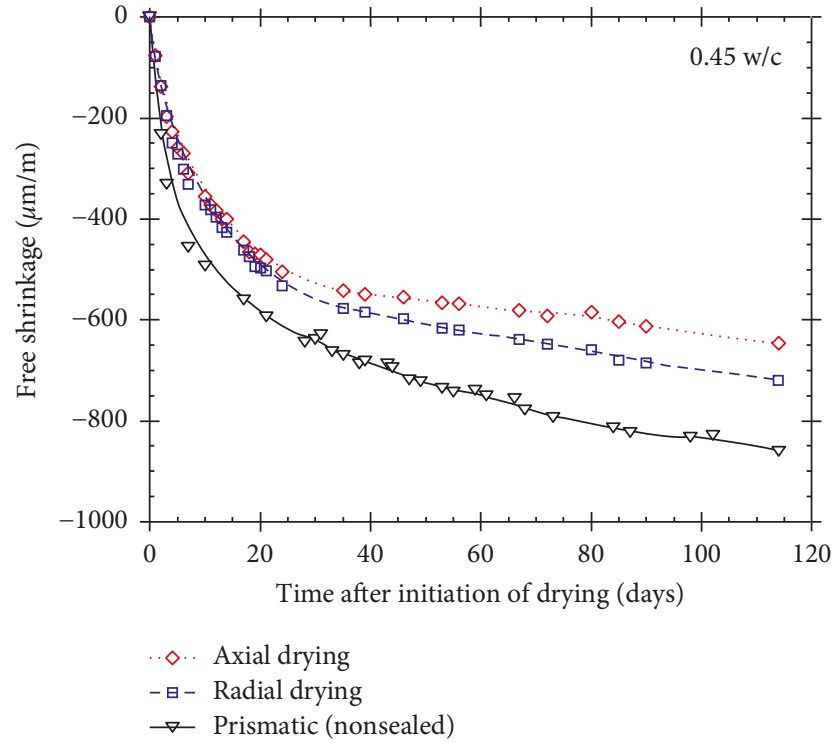

(a)

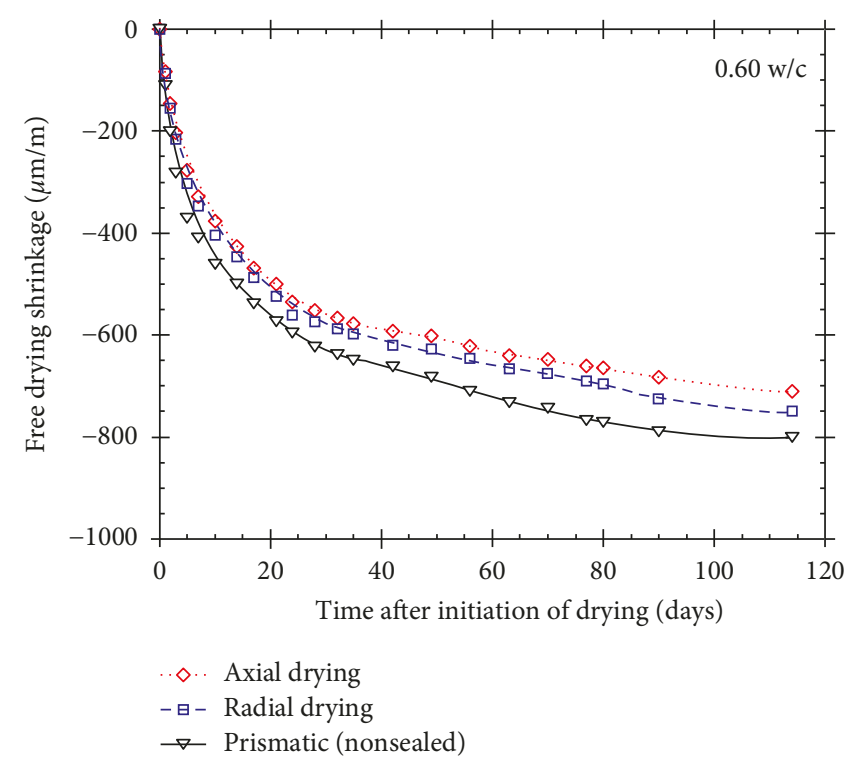

(b)

FIGURE 8: Influence of specimen geometry, S/V, and drying direction on free shrinkage recorded. (a) w/cm $0.45 \mathrm{mixture},(\mathrm{b}) \mathrm{w} / \mathrm{cm} 0.60$ mixture.

in the recorded shrinkage strain for the inner and mid-width locations compared to the outer location. This is attributed to the fact that, in specimen dried from the radial direction, moisture loss is uniform along the height direction of the specimen but not along the radial direction. In fact, the relative humidity at the outer circumferential surface is slightly higher than the ambient humidity of 50\% [17]. As a result, the ring specimen shrinks faster at the outer drying surface where more rapid drying occurs. However, the internal core (inner radius up to mid-width) dries at a slower pace. Consequently, the shrinkage at these DEMEC point locations did not vary significantly. Indeed, similar results were reported by Lim et al., [21] although in their studies the specimens were drying from all surfaces.

4.4. Effects of Specimen Geometry, Size, and Drying Condition on Free Shrinkage. The main objectives for the free ring and linear tests were to (i) study the influence of surface-tovolume ratio and drying direction on drying shrinkage using different geometries and (ii) investigate the common assumption that the magnitude of shrinkage is the same for concrete with equal $\mathrm{S} / \mathrm{V}$ ratio regardless of the geometry and boundary conditions of concrete specimens. The geometrical characteristics and S/V ratios of the prismatic and the ring specimens are summarised in Table 2. The comparison of the shrinkage recorded on the prismatic and ring specimens of unequal S/V ratio is shown in Figure 8. The free shrinkage is the average of the 3 location measurements on two ring specimens. Figure 9 shows the recorded shrinkage on prismatic and ring specimens with equal S/V ratios. The results in Figure 8 indicate that the geometry of specimens influences the evolution of drying shrinkage for both the $\mathrm{w} / \mathrm{cm}=0.45$ and 0.60 mixtures. As expected for both mixtures, higher shrinkage values were recorded on prismatic specimens with all surfaces exposed compared to ring specimens. This is partly because the prismatic specimen with all surfaces exposed (nonsealed) have higher S/V exposed to drying than the ring specimens. Also, amongst the ring test specimens, drying from the radial direction leads to higher shrinkage than drying from the axial direction. This again is attributed partly to the fact that the ring specimens drying from the radial direction have higher $\mathrm{S} / \mathrm{V}$ than specimen drying from the axial direction. In fact, this is not surprising since at a constant $\mathrm{RH}$, size, shape, geometry, and $\mathrm{S} / \mathrm{V}$ of concrete elements exposed to drying dictate the magnitude of shrinkage. This is mainly because water transport from the interior of concrete to the atmosphere (i.e., rate of water loss) is controlled by the length of the path traveled by the water, which is being expelled during drying shrinkage and/or creep [22]. Indeed, research has shown that drying direction can significantly influence the moisture profile and consequently the distribution of residual stresses inside the concrete ring [18].

Furthermore, the results in Figure 9 reveal that the general consensus implying that the magnitude of shrinkage recorded on concrete specimen with the same $\mathrm{S} / \mathrm{V}$ ratios is equal regardless of the geometry, and drying direction of concrete specimens is not entirely true.

It was observed that, for both mixtures, the average shrinkage measured on the free ring specimens is higher than that of the prismatic specimens although having the same $\mathrm{S} / \mathrm{V}$ ratio. This is true for both drying directions. The difference is more significant for the $\mathrm{w} / \mathrm{cm}=0.60$ mixture. Interestingly, the lowest shrinkage recorded in this study at the inner radius of the ring (Figure 9) is actually very close to the values recorded for the prismatic specimen with the same $\mathrm{S} / \mathrm{V}$ ratio (especially for specimens drying from the axial). In previous 


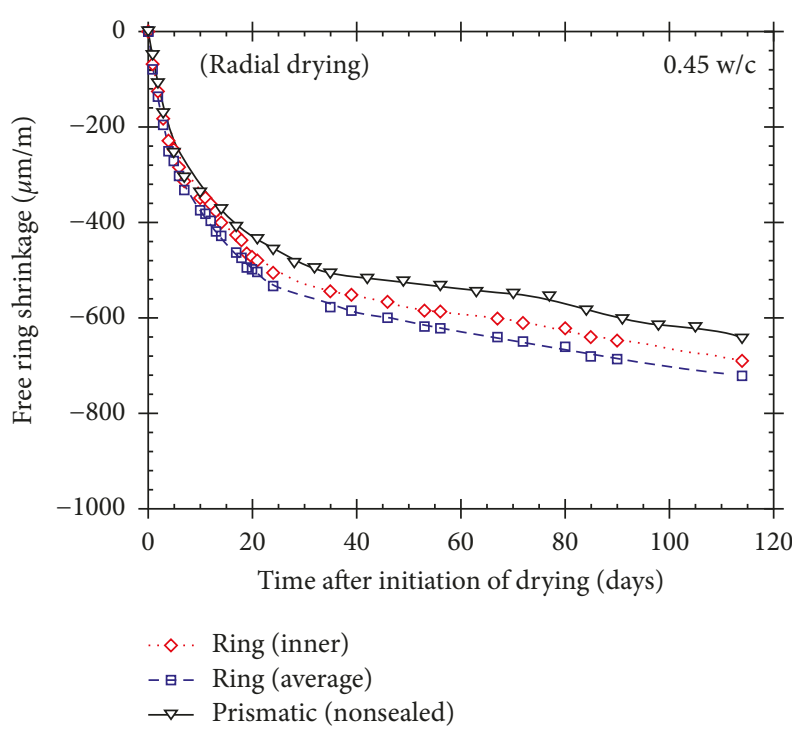

(a)

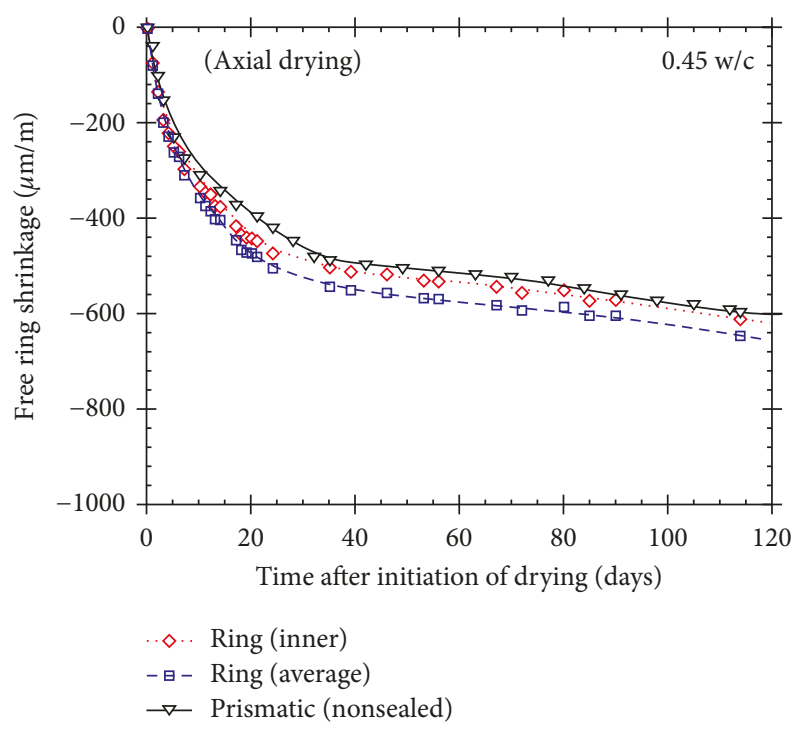

(c)

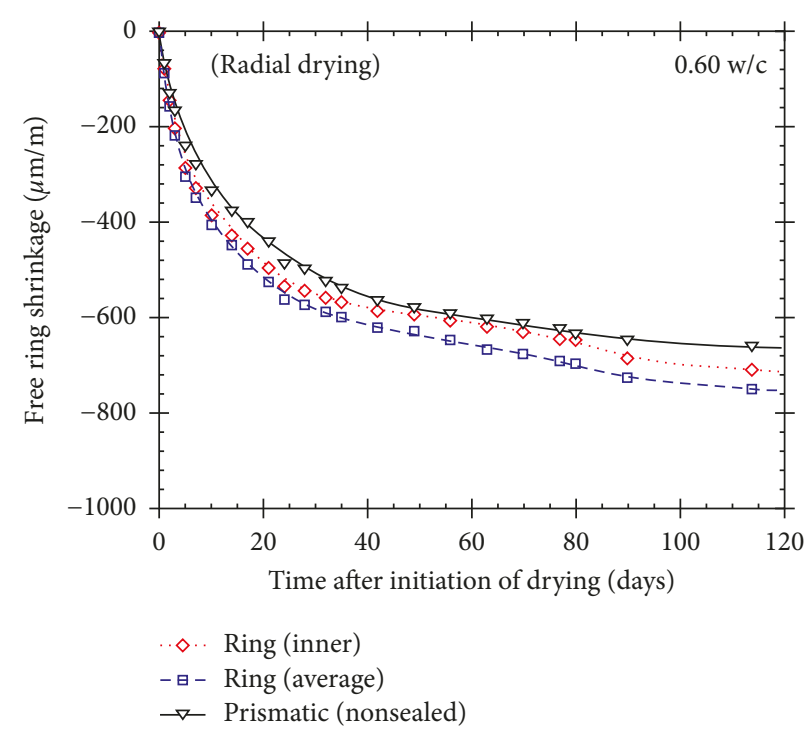

(b)

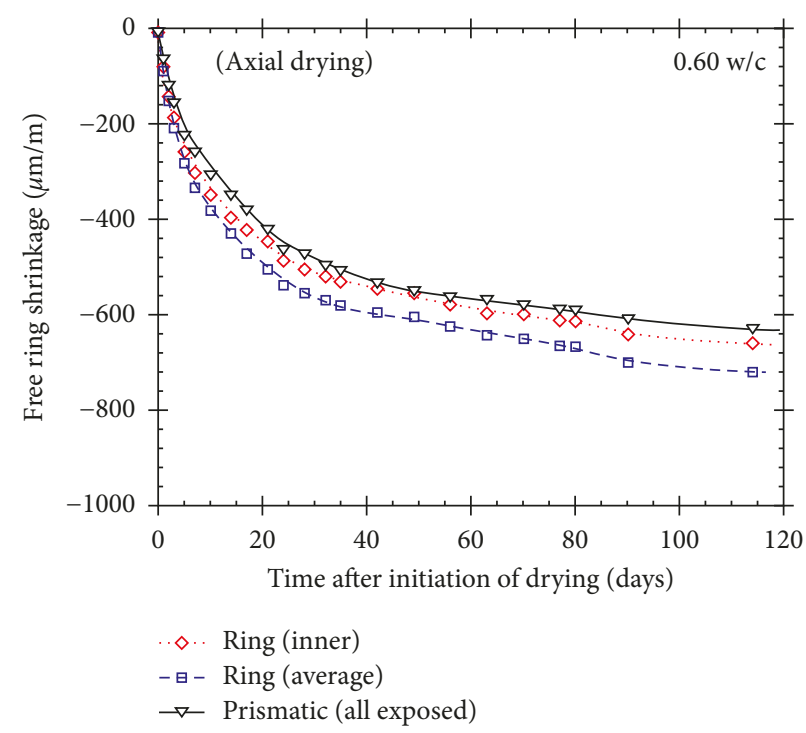

(d)

FIGURE 9: Free shrinkage recorded on prismatic and ring specimens with equal S/V ratio. (a) w/cm 0.45 radial drying specimen, (b) w/cm 0.60 radial drying specimen, (c) w/cm 0.45 axial drying specimen, (d) w/cm 0.60 axial drying specimen.

studies by Hossain and Weiss [6] however, it was found that prismatic specimens with equal $\mathrm{S} / \mathrm{V}$ ratio as ring specimens drying from the axial demonstrated similar shrinkage to measurements taken at mid-width on the ring specimen. It should be noted that the specimen used in the present study is twice the height of the specimen used by Hossain and Weiss [6]. In a nutshell, the discrepancies between the two tests are most probably to be attributed to the specimen heights. Overall, the results from this study reveal that measurements made on prismatic specimens with same $\mathrm{S} / \mathrm{V}$ as the AASHTO ring specimen in most cases will underestimate the actual magnitude of the average shrinkage. Particularly, if the test is intended to estimate the creep properties of the concrete, since the results from free and restrained ring shrinkage test are often combined to estimate creep and relaxation properties of concrete.

\section{Conclusion}

This paper focused on the study of the influence of free ring shrinkage test procedure, specimen geometry, and drying direction upon drying shrinkage. The experimental results first showed that the location at which the deformation is measured on the concrete ring has a significant influence on the recorded drying shrinkage. This study has shown that specimen geometry and drying direction also have a significant 
influence on the drying shrinkage. In addition, it has been observed that the drying shrinkage increases with an increasing surface-to-volume ratio. It has been found that the ring test specimens drying from the radial leads to higher recorded shrinkage than those drying from the axial sides. This can be explained by the fact that the specimens that dry from the outer radial have a higher surface-to-volume ratio. The widespread assumption that free shrinkage is the same for concrete with equal S/V ratio regardless of the geometry and drying direction of concrete specimens was found not to be satisfactory for the purpose of this study, that is, using the ASTM C157 specimens in conjunction with ring specimens. In fact, it was observed that even though the tested specimens had the same $\mathrm{S} / \mathrm{V}$ ratio, the shrinkage recorded on the free ring specimen was not similar to that measured the corresponding prismatic specimens. Using the average ring deformation is likely to improve the reliability of the free drying shrinkage evaluation and, in turn, of the calculated creep properties. It should be further added that experiments are under way at Universite Laval to evaluate the alternative use of prismatic specimens with the exact same cross-sections as that of the ring specimens. Although, ideally, it is recommended that similar geometry be used for both free and restrained shrinkage measurements, a complementary test method using similar cross section of a linear prismatic and AASHTO ring specimen is also necessary due to its experimental simplicity. Furthermore, the actual influence of using either free ring or prism (with same S/V) shrinkage data upon the calculated creep parameters needs to be investigated.

\section{Conflicts of Interest}

The authors declare that they have no conflicts of interest.

\section{Acknowledgments}

The authors gratefully acknowledge the support received from King Shotcrete Solutions and the Natural Sciences and Engineering Research Council of Canada through their Collaborative Research and Development program. This project is part of a long-term effort to reduce the cracking potential of concrete and shotcrete repairs and to improve their service life. This work was conducted at CRIB (Centre de recherche sur les infrastructures en béton), Université Laval, and the authors are grateful to Mr. Jean-Daniel Lemay and $\mathrm{Mr}$. Mathieu Thomassin for their outstanding technical support.

\section{References}

[1] S. Altoubat, "Early age creep and shrinkage of concrete with shrinkage reducing admixtures (SRA)," Jordan Journal of Civil Engineering, vol. 4, no. 3, pp. 281-291, 2010.

[2] W. J. Weiss, W. Yang, and S. P. Shah, "Using fracture to predict restrained shrinkage cracking: the importance of specimen geometry," ACI Special Publication, vol. 201, pp. 17-34, 2001.

[3] R. Mishra, R. Tripathi, and V. Dubey, "Early age shrinkage pattern of concrete on replacement of fine aggregate with industrial by-product," Journal of Radiation Research and Applied Sciences, vol. 9, no. 4, pp. 386-391, 2016.

[4] L. Iures, C. Badea, S. Dan, and C. Bob, "Assessment of cracking index and characteristic contraction due to concrete' shrinkage," in Proceedings of International Multidisciplinary Scientific GeoConference, SGEM: Surveying Geology \& Mining Ecology Management, vol. 361, Albena, Bulgaria, June-July 2013.

[5] ASTM-C157, Standard Test Method for Length Change of Hardened Hydraulic-Cement Mortar and Concrete, ASTM International, West Conshocken, PA, USA, 2014.

[6] A. B. Hossain and J. Weiss, "The role of specimen geometry and boundary conditions on stress development and cracking in the restrained ring test," Cement and Concrete Research, vol. 36, no. 1, pp. 189-199, 2006.

[7] B. Pease, F. Rajabipour, J.-H. Moon, and J. Weiss, "Quantifying the influence of specimen geometry on the results of the restrained ring test," Journal of ASTM International, vol. 3, no. 8, pp. 1-14, 2006.

[8] G. Lomboy, K. Wang, and C. Ouyang, "Shrinkage and fracture properties of semiflowable self-consolidating concrete," Journal of Materials in Civil Engineering, vol. 23, no. 11, pp. 1514-1524, 2010.

[9] K. V. Subramaniam and A. K. Agrawal, Concrete deck material properties, 2009.

[10] AASHTO-PP-34-99, Standard Practice for Estimating the Cracking Tendency of Concrete, American Association of State Highway and Transportation Officials, Washington, DC, USA, 1999.

[11] H. T. See, E. K. Attiogbe, and M. A. Miltenberger, "Shrinkage cracking characteristics of concrete using ring specimens," ACI Materials Journal, vol. 100, no. 3, 2003.

[12] A. Hossain, B. Pease, and J. Weiss, "Quantifying early-age stress development and cracking in low water-to-cement concrete: restrained-ring test with acoustic emission," Transportation Research Record: Journal of the Transportation Research Board, vol. 1834, pp. 24-32, 2003.

[13] P. Van Itterbeeck, N. Cauberg, B. Parmentier, L. Vandewalle et al., "Evaluation of the cracking potential of young self-compacting concrete," in Proceedings of the 6th International RILEM Symposium on SCC, Montréal, QC, Canada, September 2010.

[14] ACI-506R-16, Guide to Shotcrete, American Concrete Institute, Farmington Hills, MI, USA, 2016.

[15] S. Girard, M. Jolin, B. Bissonnette, and J.-D. Lemay, "Measuring the cracking potential of shotcrete," Concrete International, vol. 39, no. 8, pp. 44-48, 2017.

[16] J. A. Almudaiheem and W. Hansen, "Effect of specimen size and shape on drying shrinkage of concrete," Materials Journal, vol. 84, no. 2, pp. 130-135, 1987.

[17] W. Dong, X. Zhou, Z. Wu, and G. Kastiukas, "Effects of specimen size on assessment of shrinkage cracking of concrete via elliptical rings: thin vs. thick," Computers \& Structures, vol. 174, pp. 66-78, 2016.

[18] J. H. Moon and J. Weiss, "Estimating residual stress in the restrained ring test under circumferential drying," Cement and Concrete Composites, vol. 28, no. 5, pp. 486-496, 2006.

[19] R. N. Swamy, "Dynamic Poisson's ratio of portland cement paste, mortar and concrete," Cement and Concrete Research, vol. 1, no. 5, pp. 559-583, 1971.

[20] R. Mors, Autogenous shrinkage of cementitious materials containing BFS, M.S. thesis, Delft University of Technology, Delft, Netherlands, 2011.

[21] J.-S. Lim, S.-H. Kim, and J.-H. Jeong, “Testing and analysis of viscoelastic characteristics of solidifying concrete pavement slabs," KSCE Journal of Civil Engineering, vol. 18, no. 4, pp. 1063-1071, 2014.

[22] P. Mehta, P. J. K. Mehta, and P. J. Monteiro, Concrete: Microstructure, Properties, and Materials, McGraw Hill Education, New York, NY, USA, 2006. 

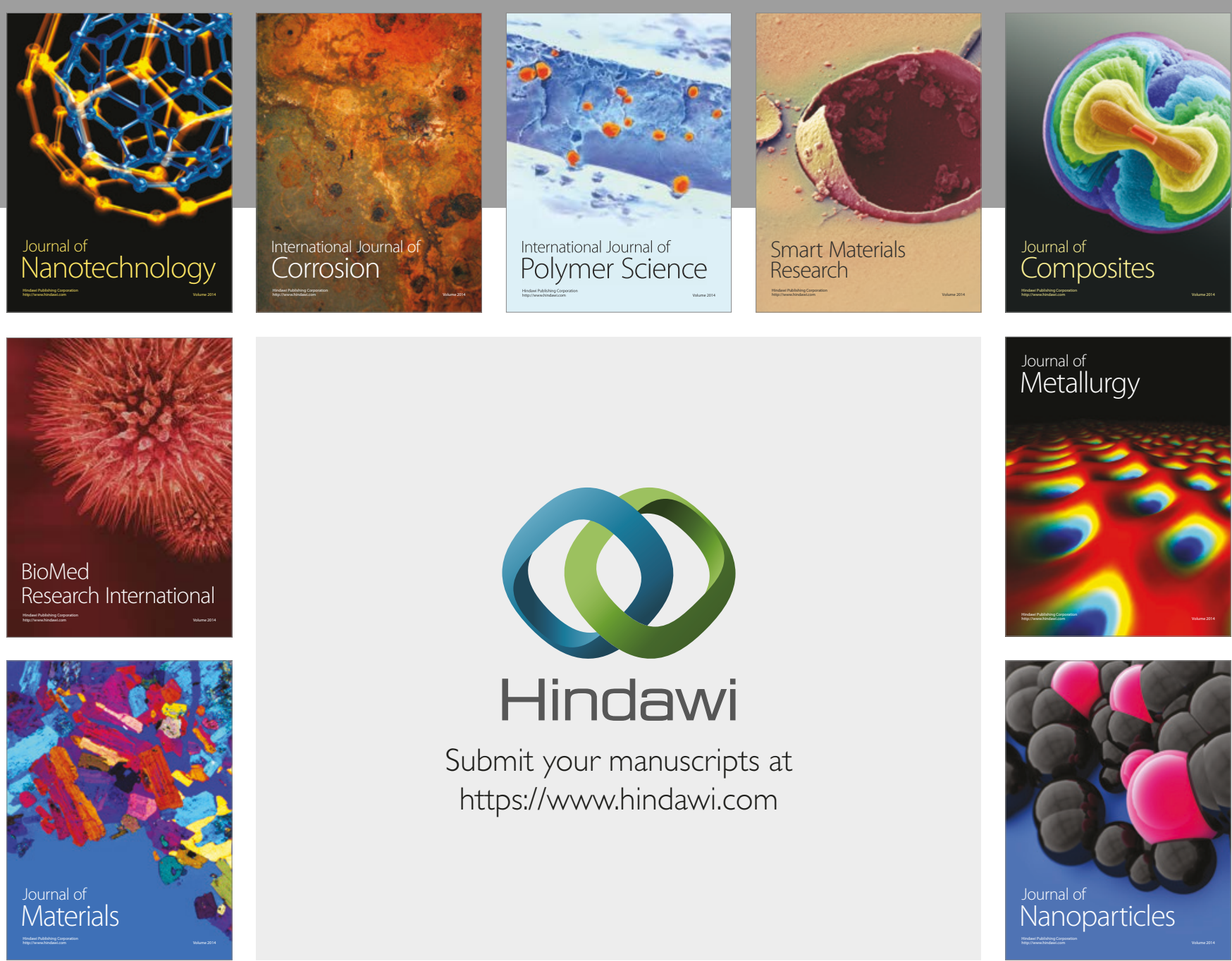

\section{Hindawi}

Submit your manuscripts at

https://www.hindawi.com
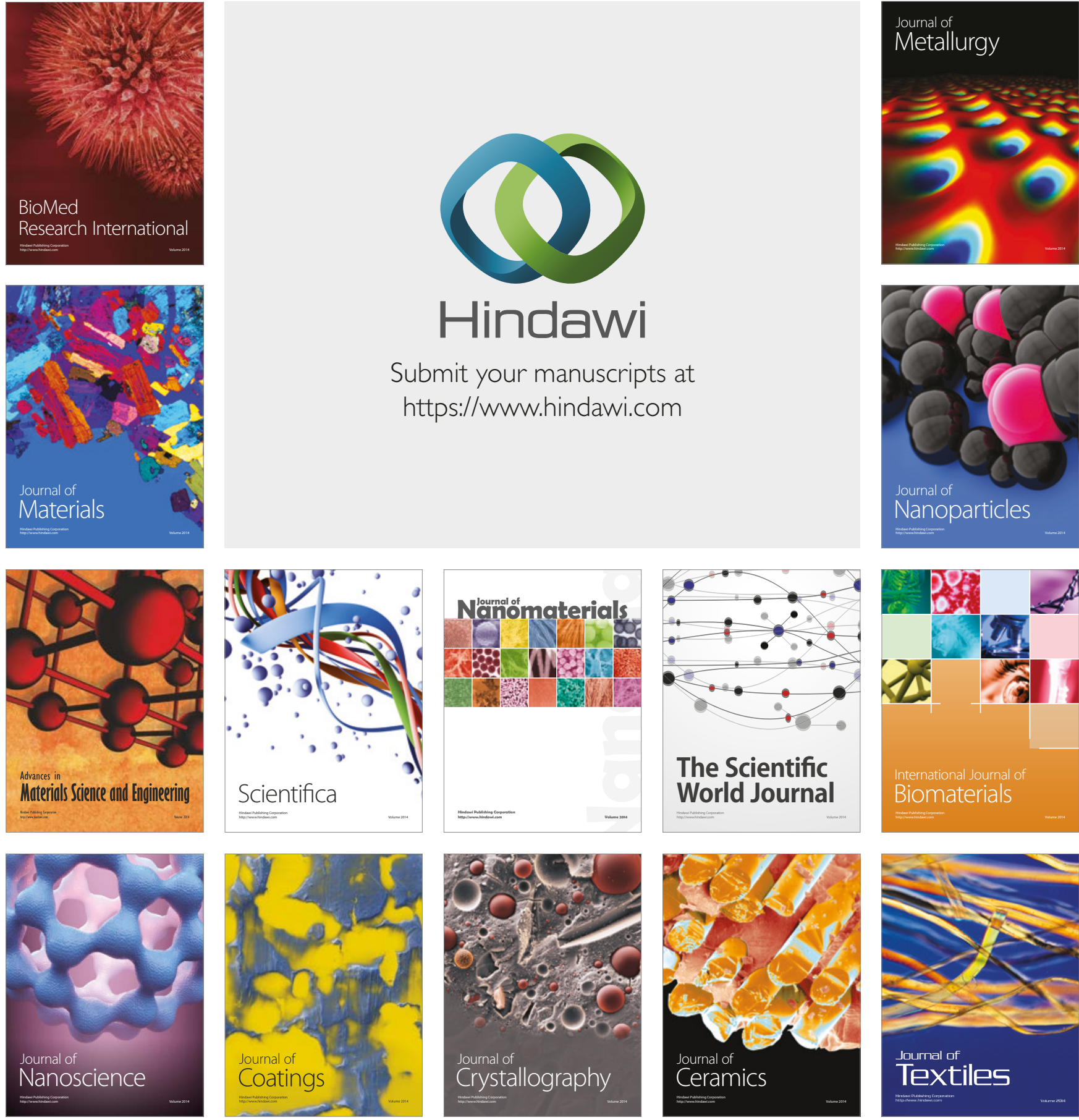

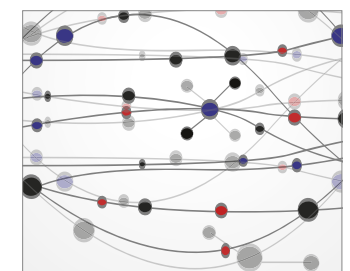

The Scientific World Journal
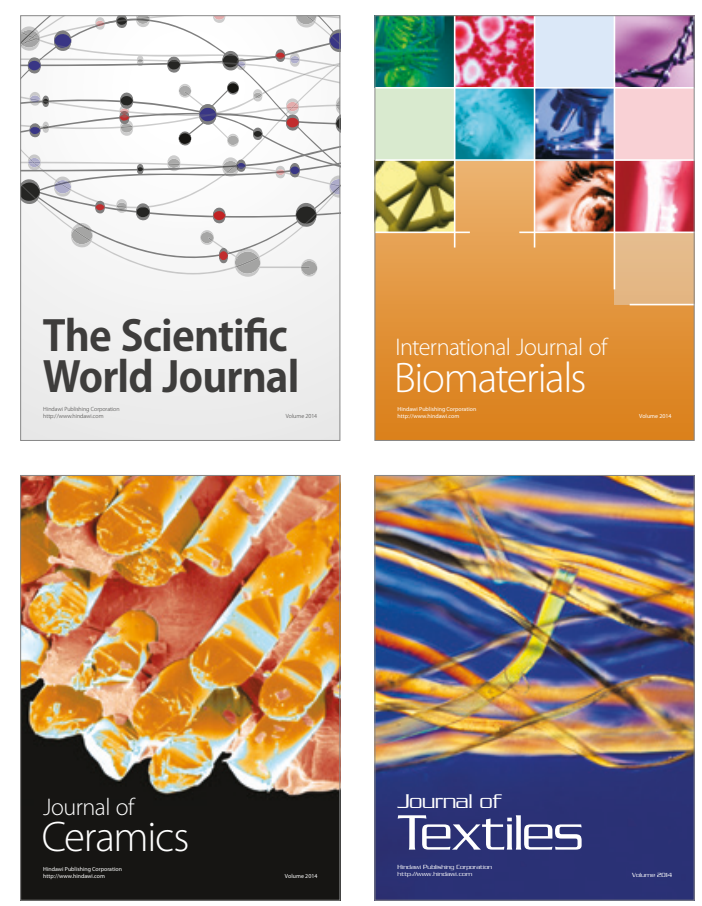